\title{
Characterization of vine varieties by SSR markers
}

\author{
Ivana Dokupilováa, b, Ernest Šturdík ${ }^{\text {a, c }}$, Daniel Mihálik \\ ${ }^{a}$ Department of Biotechnology, Faculty of Chemical and Food Technology of Slovak University of Technology, \\ Radlinského 9, 81237 Bratislava, Slovakia \\ ${ }^{b}$ Department of Molecular Biology, The Plant Production Research Centre - Pieštany, \\ Institute of Viticulture and Enology, \\ Bratislavská cesta 122, 92168 Pieštany, Slovakia \\ ${ }^{c}$ Department of Biotechnology, Faculty of Natural Science of University Ss. Cyril and Metodius in Trnava, \\ J. Herdu 2, 91701 Trnava, Slovakia \\ dokupilova.ivana@gmail.com
}

\begin{abstract}
Nowadays, there are well known PCR-based techniques to detect polymorphism in plants. Marker technologies which are applied in breeding and varietal characterization can be exchanged across laboratories with standardization to yield reproducible results. This article describes applying of simple sequence repeats (SSR) markers in European laboratories, in which the reproducibility of these popular markers are examined. One of the European Union interests is characterization of grape varieties and preparation of International Vitis catalogue for comparison global varieties as Chardonnay, Sauvignon, Pinot noir with the domestic for each other country. Grape genome contains of many SSR, which are highly polymorphic.

This review provides the latest information in SSR research including novels in research, comparison, development and application of microsatellites.
\end{abstract}

Keywords: Microsatellites - SSR, vine varieties, polymorphism, Vitis vinifera

\section{Introduction}

Microsatellites became the favourite type of DNA markers due to their properties including enabling a wide range of applications, from cultivar identification and discrimination, to phylogenetics, parentage testing and pedigree reconstruction, for the management of germplasm collections (Laucou et al., 2011, Sefc et al., 2000, Thomas et. al. 1998; Bowers et al., 1999; Sefc et. al., 1999).

Microsatellite markers consist from the repetition of simple nucleotide motifs and are highly expanded in eukaryotic genomes. Due to their high degree of polymorphism, locus-specificity, and PCR-based detection, they are powerful genetic markers for animals as well as for plants. In plants, SSR markers have been successfully applied to a variety of tasks including the construction of genetic maps, the assessment of genetic diversity, cultivar identification pedigree studies (Ghetea et al., 2010; Riaz et al., 2004, Sefc et al. 1999). Microsatellites in woody plants have been reported for wheat (Varshney et al., 2005, Song et al., 2005, Gupta et al., 2003, Eujail et al., 2002), pineapple (Carlier et al., 2010), rice (Varshney et al., 2005, McCouch et al., 2002), bean (Li-Xia et al., 2009) grapevine (Cipriani et.al., 2010, Jahnke et al. 2010 Bowers et al. 1997), tomato (MENG et al. 2010), jujube (Ma et al., 2011), citrus(Oliveira et al., 2002), apricot (Aranzana et al. 2003; ; Maghulyet. al., 2005; Cheng et. al, 2009;
Wunsch, 2009; Lamia et al., 2010), peach (Xie et al., 2010), and maize (Cheng et al, 2010, Jiang et al., 2008). Microsatellite markers are widely used in grape-vine genetic research for identifying cultivars (Bowers et al., 1999, Kozjak et al., 2003), investigating the parentage of cultivars (Ghetea et al., 2010, This et al., 2004), genome mapping (Carlier et al., 2010, Troggio et al., 2007), geographic origin (Sefc et al, 2000) and genetically characterizing germplasm (Upadhyay et al., 2007, Lamia et al., 2010).

\section{Analyses and comparison of different type of microsatellites}

Numerous methods were tested with the goal to provide a reliable method of genotype identification and inter-laboratory comparison. Highly informative markers became an available technique for the management of germ-plasm collections. This method can be potentially used as an accurate certification system for global international trade of grapevine and rootstock plant material (Sefc et al., 2000).

The traditional identification methods for differentiation cultivars, ampelography and ampelometry, are based on the shape and contours of the leaves, the characteristics of growing shoots, shoot tips, petioles, the sex of the flowers, the shape of the grape clusters and the colour, size and pips of the grapes themselves. New view brought advances in 
DNA sequencing, data analysis and PCR which gave results in powerful techniques which can be used for the characterisation and evaluation of germplasm (Upadhyay et al., 2007) and genetic resources (Troggio et al., 2007) and for the identification of markers for use in breeding programmes (Vignani et al., 1996). Wide-scale applications of these techniques should be suitable for use in network activities in which many laboratories may be involved in coordinated actions and in which common data-bases are continually fed with data. It is essential for activities that the different screening techniques employed can be standardised to yield reproducible results across laboratories, so that direct collation and comparison of the data are possible (Jones et al., 1997).

There are known several techniques which can be used for the characterisation and evaluation of germplasm and genetic resources, and for the identification of markers for use in breeding programmes.

First technique is random-amplified polymorphic analysis (RAPDs) which involves the use of a single arbitrary primer in a PCR reaction and result of amplification is several discrete DNA products. These products are derived from a genome region which contains two short segments in inverted orientation that are templates for design of primer sequences and sufficiently close together for the amplification.

This analysis is a cheap, easy and fast method for the detection of genetic differences between organisms. RAPD analysis gave the satisfying levels of polymorphism which were detected in grapevine and rootstock cultivars (Tessier et al. 1999, Jones et al. 1997, Fan-Juan et al. 2010). On the other hand, the major disadvantage of this method is the dependence of the results on strict experimental conditions.

Stability of the results can be achieved by strict laboratory standardized reaction conditions, but to achieve the satisfactory results of standardisation of the RAPD procedure and comparison of the results between laboratories is a difficult goal Fig. 1 (Sefc et al., 2000).

Amplified fragment length polymorphism (AFLP) analysis is another PCR-based method which involves restriction cleavage of the genomic DNA (Upadhyay et al., 2007, Lamia et al., 2010). Adapters are ligated to the ends of the restricted fragments and either a pre selection step performed using magnetic beads followed by a round of selective PCR, or two selective rounds of PCR amplification are applied. The amplified products are separated on a sequencing gel by electrophoresis and after that visualised by radioactive or fluorescent labelling. All the current evidences show that AFLPs are as reproducible as restriction fragment length polymorphism (RFLP). This method should be highly suited to inter-laboratory experiments (Jones et al., 1997).

RFLP analysis was successfully used to detect cultivar fingerprints to differentiate varieties of grapevine and rootstock (Fig. 2). The RFLP method offers the advantages of robustness in various environments and higher levels of detectable polymorphism as

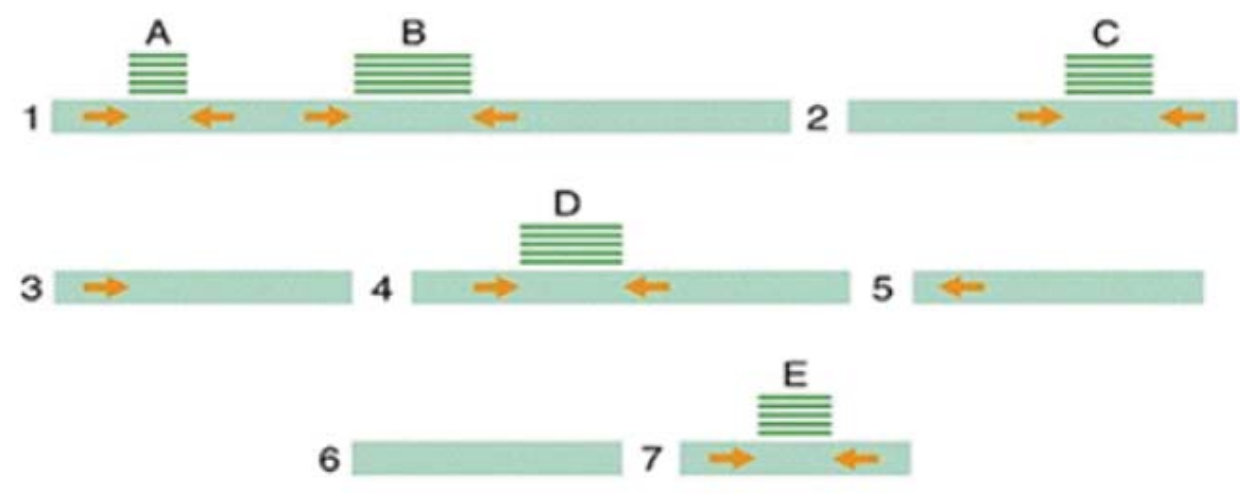

Electrophoresis of PCR product

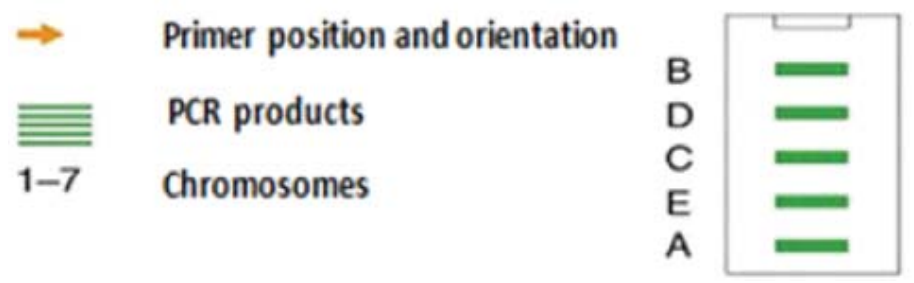

Fig. 1. Example of random-amplified polymorphic analysis (Technologijahrane, 2011). 


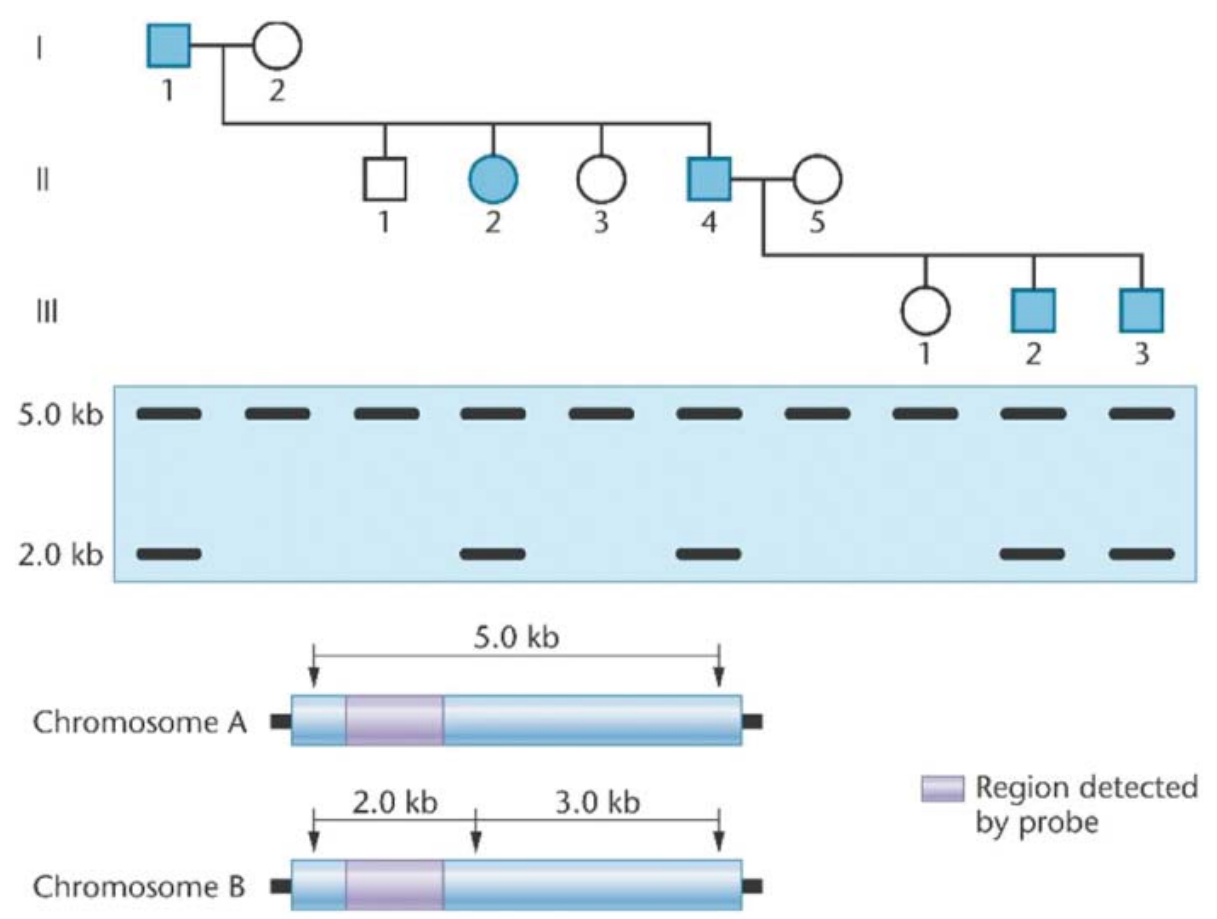

Fig. 2. Example of restriction fragment length polymorphism analysis (Nicerweb, 2011).

iso-enzyme analysis; identification of varieties by distribution of different enzymes. On the other hand, complicated banding patterns may cause difficulties in the evaluation of results and the requirement of large amounts of high quality DNA, as well as the time-consuming and costly primary development of probes and costly analysis procedure (Sefc et al., 2000).

SSR markers, also known as short tandem repeats (STRs) or microsatellites consist of tandem repeated DNA sequences with 1-6 base pairs (bp). These markers are in abundance distributed in plant genomes; they have high level of variability in the number of repeats of the core motif, occasionally showing dozens of alleles at each locus. They are amplified by PCR using a primer pair that anneals to the repeat flanking regions and therefore tag a single locus in diploid genomes. The other advantage is their high reproducibility between laboratories without requiring any DNA exchange (Zhang et al., 2010, Martínez et al., 2006,). These markers which are locus-specific are characterized by their hyper-variability, abundance, high reproducibility, Mendelian inheritance and co-dominant nature. They are not affected by the environmental factors (soil, climate, methods of cultivation, diseases) influences (Ghete et al, 2010 Giannetto et al., 2008). SSRs provide highly informative markers because they are co-dominant (unlike RAPDs and AFLPs) and generally highly polymorphic. The nature of the PCR-based assay used in their amplification and detection provide the confirmation that they are highly reproducible between laboratories (Jones et al., 1997).

Jones et al. (1997) described the reproducibility of testing different type of markers in plants by a network of European laboratories. This article described three popular molecular marker techniques which were examined in several European laboratories for testing reproducibility: RAPD, AFLP and SSR. RAPDs were found to be easy to perform by all laboratories, but reproducibility was not achieved to a satisfactory level. The system of genetic screening package was distributed to different participating laboratories in the network and the results obtained compared with those of the original sender. Disadvantage of RAPD methods were their problems with reproducibility. For AFLPs, a single-band difference was observed in one track, while SSR alleles were amplified by all laboratories, but small differences in their sizing were obtained.

Microsatellite analysis can be applied to the confirmation and definition of synonyms and homonyms, i.e. identical genotypes known under different names or different genotypes under the same names (Ulanovsky et al., 2002). The identification of duplicates is important in germplasm collections to save genetic variability should be maintained while keeping the number of specimens at minimum. For several cultivars, synonyms and homonyms had been suspected or assumed based on ampelographic observations and could be confirmed by microsatellite analysis (Cipriani et al., 2010). 


\section{Design of primer sequences}

The aim of the work of many European workplaces was to develop a microsatellite marker-based map of the Vitis vinifera genome $(\mathrm{n}=19)$, which can be used for genetic studies in perennial heterozygous species, as SSR markers are highly transferable codominant markers (Adam-Blondon et. al, 2004).

The most important for development of microsatellites is a fresh material from young plants at identical developmental stages. The next step to develop the molecular markers was the analysis at the DNA level, since the DNA of a certain plant is identical in all cells of any tissue at any stage of development. DNA can be obtained from every kind of plant tissue available, e.g. wood, leaves or berries, but the easiest is DNA extraction from leaves and analyses can therefore be carried out at any time of the year. DNA characteristics are not influenced by environmental or sanitary conditions of the plants. Thus, DNA based analyses are free from various kinds of external limitations (Sefc et al., 2000).

The most usual microsatellite sequence consists of five to one hundred tandem repeats of short, simple sequence motives composed from 1 to 6 nucleotides (e.g. (CA)n, (GATA)n; Fig. 3). About 104 to 105 microsatellite loci are scattered randomly throughout the genome of eukaryotes. This abundance of microsatellite sequences in eukaryotic genomes constitutes an almost unlimited source of polymorphic sites that may be exploited as genetic markers. Microsatellite markers are usually not located inside or close to a coding sequence, where they may cause the disruption of gene function or be influenced by selection pressures on a gene in their vicinity (Sefc et al., 2000).

Before the availability of the polymerase chain reaction (PCR), microsatellites were used for fingerprinting eukaryotic genome by classical hybridization method (Vezzulli et al. 2008, Jahnke et al. 2007). Big advantages of microsatellite markers are both locus specificity and their high polymorphism. Allele sizes are resolved by the high-resolution electrophoresis. The markers are co-dominant and thus allow the discrimination of homozygotes and heterozygotes. Microsatellite profiles are represented by the allele sizes detected at the analysed loci and given in base pairs. Disadvantages of microsatellite markers used for detection of relationships between organisms are cost of this method, time consuming procedure including optimizing of PCR conditions, primers and construction and screening of genomic libraries. Fortunately, microsatellite primers which are design for one species are very often similar in closely related species of the same genus and even sometimes genera such as in case of Vitis vinifera and Vitis riparia. There have been published microsatellite markers from Vitis vinifera and Vitis riparia, which amplified DNA from other Vitis species (Sefc et al., 2000).

Reproducibility and standardization of microsatellite profiling is usually easy to achieve and after allow transfer and comparison between laboratories (Sefc et al., 2000).

Bowers et al. 1999 studied microsatellite markers and twenty of these (Table 1,2) were polymorphic in $V$. vinifera and produced satisfactory results. As with other grape microsatellite markers, they are highly heterozygous and very informative in $V$. vinifera (Table 1).

\section{Methods of analysis and their comparison}

Different methods are applied in analysing microsatellite markers, for example incorporation ${ }^{35} \mathrm{~S}$

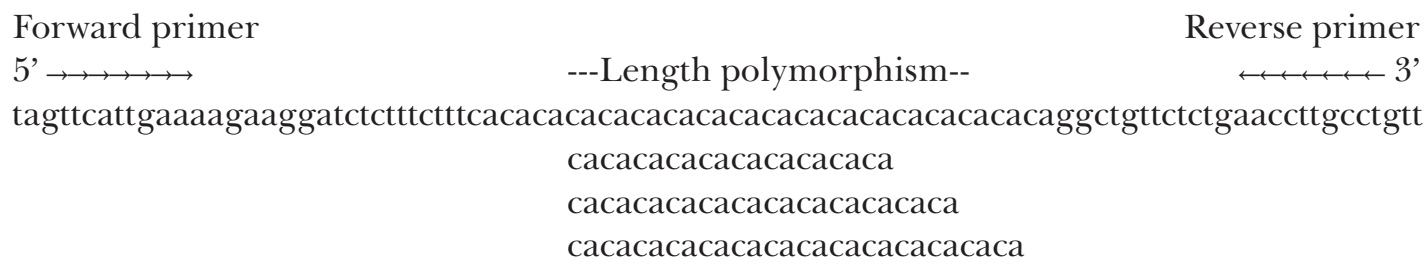

\section{- Description}

SSR markers consist from tandem repeats of short nucleotide motifs ( 1 to $6 \mathrm{bp}$ ), have a low degree of repetition (5-100 repeats). They are randomly distributed in the genome and the length polymorphism can be detected by PCR amplification and electrophoresis.

\section{- Advantages}

SSR markers have several advantages, locus-specific amplification, frequent occurrence, high polymorphism, a co-dominant inheritance and are distributed throughout the nuclear genome.

Fig. 3. A dinucleotide microsatellite locus (Sefc et al., 2001). 
Tab. 1. Primer sequences for 12 microsatellite markers that are polymorphic in V. vinifera. (Bowers et. al, 1999).

\begin{tabular}{lll}
\hline Locus & Primer + & Primer - \\
\hline VVMD14 & CATGAAAAAATCAACATAAAAGGGG & TTGTTACCCAAACACTTCACTAATGC \\
VVMD17 & TGACTCGCGAAAATGTGACG & CACACATATCATCACCACACGG \\
VVMD21 & GGTTGTCTATGGAGTTGATGTTGG & GCTTCAGTAAAAAGGGATTGCG \\
VVMD24 & GTGGATGATGGAGTAGTCACGC & GATTTTAGGTTCATGTTGGTGAAGG \\
VVMD25 & TTCGGTTAAAGCAAAAGAAAAAGG & TTGGATTTGAAATTTATTGAGGGG \\
VVMD26 & GAGACGACTGGTGACATTGAGG & CCATCACCACGATTTCTACTGC \\
VVMD27 & GTACCAGATCTGAATACATCCGTAAGT & ACGGGTATAGAGCAAACGGTGT \\
VVMD28 & AACAATTCAATGAAAAGAGAGAGAGAGA & TCATCAATTTCGTATCTCTATTTGCTG \\
VVMD31 & CAGTGGTTTTTCTTAAAGTTTCAAGG & CTCTGTGAAAGAGGAAGAGACGC \\
VVMD32 & TATGATTTTTTAGGGGGGTGAGG & GGAAAGATGGGATGACTCGC \\
VVMD34 & GGTACATCAGTACTTGAAATGGTTGC & TTCTCCGTAGAAGCGTAAACAGC \\
VVMD36 & TAAAATAATAATAGGGGGACACGGG & GCAACTGTAAAGGTAAGACACAGTCC \\
\hline
\end{tabular}

Tab. 2. Primer sequences for 10 microsatellite markers of lesser utility in V. vinifera (Bowers et. al, 1999).

\begin{tabular}{lll}
\hline Locus & Primer + & Primer - \\
\hline Polymorphic but less useful & \\
\hline VVMD20 & AAAACACATATTCAAACCAACCCG & AACACCCTCCCTCTCCTACTCC \\
VVMD23 & ATGGTTCGATGGATGGATGG & AAGTATGAAGCGAGTGCAGGC \\
VVMD29 & CCTTTGAACTTTGAAGTCTATGAGTCTG & AGCTAGAAACAGAACTCTCTCTCTCTC \\
VVMD30 & CGAAAGAATTCCCAAAGGGC & TCTAGGCACTCTTTTCGGTACTCC \\
VVMD37 & GATCGCCTTGTAATCCAAAAGG & GATCTGAACTAACCCAAGAAGAGAGC \\
\hline Ussually monomorphic & \\
\hline VVMD 12 & CCTTCTGTATAGCAACGTCTGA & TTCCCTCATATTTGAACAGTCT \\
VVMD 13 & ATGGTGAAAGAAGCAGAGAGGG & GCATTGAAGATGACCGGTAGC \\
VVMD15 & CTGCAGTGCACTCAAAGTTGG & TGAAACACCAAGGGAAACCTC \\
VVMD19 & TGAAATATCATCAATGCTCTCTCTCG & GGTTGATATTGCTTCCTTTTCCG \\
VVMD35 & GAGGAAGACTCCTCACGTAGAAGG & TCAACAAACATACCGAGGAACG \\
\hline
\end{tabular}

dATP or ${ }^{33} \mathrm{P}-\mathrm{dATP}$ during the PGR and separation of the products on polyacrylamide gels (Jones et.al., 1997, Thomas and Scott, 1993), ${ }^{32} \mathrm{P}$ end-labelled primers in the amplification reaction and separation on denaturing polyacrylamide gels, ethidium bromide staining of non-denaturing polyacrylamide gels, hybridisation of end-labelled $\left({ }^{32} \mathrm{P}\right.$, biotin); microsatellite oligonucleotide probes to fragments are transferred to nylon membranes after that are separated on denaturing polyacrylamide gels and silver stained to denaturing polyacrylamide gels (Meng et. al. 2010, Thiel et. al. 2003). Primers labelled by fluorochromes and fragment separation on denaturing polyacrylamide gels were shown as the most effective methods. The configurations used by a number of different groups including Sefc et al. (2000).

In the present time, the fluorescent labelling is more often applied, which include the possibility of multiplexing loci in a single lane with an internal size standard and automated size calling of the alleles. (Kozjak et al. 2003, Adam-Blondon et al. 2004). Allele size calling between gels and different gelbased ABI sequencing machines have shown a high reproducibility, however the major disadvantage of different methods is the comparison of obtained results between laboratories because of differences in size calling coming from different electrophoresis systems. For example, an allele estimated to be $150 \mathrm{bp}$ by silver staining may run at $148 \mathrm{bp}$ in the Pharmacia system, while it may be called 153 by the ABI sequencer. These deviations, however, are constant within a certain locus, and can easily be determined by analysing a small set of genotypes in each of the systems. Later on, the allele sizes determined by different systems can be corrected for the observed deviation to one established standard system, and data from different sources become easily comparable again. Another possibility making the comparison of data is the presentation of 
microsatellite profiles by the actual number of repeat motifs in each allele (Sefc et al., 2000).

\section{Analysis of microsatellite data}

Microsatellite profiles from grapevine cultivars can be evaluated according to different perspectives according to Sefc et al. (2000):

a) Management of germplasm collections:

- identification of cultivars

- identification of synonyms

- reconstruction of pedigrees

b) Evaluation of microsatellite markers:

- level of polymorphism

- allele frequencies

- frequency of null alleles

c) Characterisation of grapevine gene pools:

- genetic variability,

- allelic and genotypic composition

- differentiation among gene pools

d) Cluster analysis:

- establishment of similarity or distance measures

- construction of phenograms

\section{Creating the phylogenetic tree}

A phylogenetic tree or evolutionary tree is a branching diagram or "tree" showing the inferred evolutionary relationships among various biological species or other entities based upon similarities and differences in their physical and/or genetic characteristics. The taxa joined together in the tree are implied to have descended from a common ancestor (Huelsenbeck et al., 2001).

In a rooted phylogenetic tree, each node with descendants represents the inferred most recent common ancestor of the descendants and the edge lengths in some trees may be interpreted as time estimates. Each node is called a taxonomic unit. Internal nodes are generally called hypothetical taxonomic units (HTUs) as they cannot be directly observed. Trees are useful in fields of biology such as bioinformatics, systematics and comparative phylogenetics (Shimodaira, 2002).

Although phylogenetic trees produced on the basis of sequenced genes or genomic data in different species can provide evolutionary insight, they have important limitations. They do not necessarily accurately represent the species evolutionary history. The data on which they are based is noisy; the analysis can be confounded by horizontal gene transfer, hybridization between species that were not nearest neighbours on the tree before hybridisation takes place, convergent evolution, and conserved sequences (Shimodaira, 2002, Huelsenbeck et al., 2001).

\section{Simple sequence repeat markers in Europe}

Lopes et al. (2006) characterized Portuguese grapevines based on microsatellite markers. A set of 46 grapevine denominations was genotyped at 11 microsatellite loci in order to discriminate them. Comparison of the data obtained in this study with data of 32 genotypes previously reported enabled the detection of three parent offspring relationships, and identified other putative parent/progeny relationships. These data allowed understanding the origin of some Portuguese cultivars. The integration of the obtained data with ampelographic characteristics would be very important for the accurate identification of the Portuguese cultivars and can become a significant tool for the certification of quality wines produced in specific regions.

Moreno-Sanz et al. (2011) made study presenting the evaluation and identification of the phytogenetic resources of the Asturian (Northern Spain) grapevine. A total of 293 accessions were collected in old vineyards and analyzed through nine microsatellite markers. Forty-two different genotypes were obtained, including six profiles with allelic variations. Only 27 cultivars were identified when compared with national and international databases; some of them had not been found in this region before. Homonyms and synonyms have also been detected. These results provide an overview of the status of current grapevine phytogenetic resources in Asturia. Despite the substantial genetic erosion that the Asturian vineyard has suffered, a higher variability than expected has been detected. The finding of new grapevine genotypes is a fact of great importance. The genetic grapevine resources are being drastically reduced all over the world, so this new genetic material has to be included in germplasm-banks for its conservation and further agronomical and enological evaluation.

The aim of Jahnke et al. (2006) work was to investigate the genetic diversity of grapevine with SSR markers in Hungary. The microsatellite profiles in 6 loci (VVS2, VVS16, VVMD7, VMC4A1, VMC4G6, VrZag79) of 48 grapevine varieties were analyzed. Based on the SSR analyses 46 of the 48 investigated varieties were identified. Even 'Pinot blanc' and 'Pinot gris' cultivars belonging to the same consult (Pinot) could be differentiated in their VMC4A1 locus.

Schneider et al. (2001) analyzed thirty-one grape cultivars by RAPD and SSR markers to verify 25 synonym hypotheses in France and Northwestern Italy. RAPD analyses were performed with 8 selected primers and profiles with 7 microsatellite loci were used in other to confirm RAPD results, it required. Sixteen clones were confirmed, 
including the French cv. Verdesse with the Italian cv. Bianver, the French cv. Persan with the Italian cv. Biquet, the French cv. Chatus with Italian cv. Neiret.

\section{Conclusion}

Simple sequence repeat markers are the most favourite type of DNA markers because of their properties enabling a wide range of applications, from cultivar identification and discrimination, to phylogenetics, parentage testing and pedigree reconstruction, for the management of germplasm collections.

Characterization by molecular markers is more reliable compared with the amphelographic characterization because of testing possibility during all year, better exactness and possibility of comparison across European laboratories. Nowadays, finding the ancient varieties without virus infections is almost impossible and for this reason the genetic collections are created more often in all European countries.

\section{Acknowledgement}

This work was supported by Slovak research and develop ment agency APVV-0550-11.

\section{References}

Adam-Blondon AF, Roux C, Claux D, Butterlin G, Merdinoglu D, This P (2004): Theor. Appl. Genet. 109: 1017-1027.

Aranzana MJ, Pineda A, Cosson P, Dirlewanger E, Ascasibar J, Cipriani G, Ryder CD, Testolin R, Abbott A, King GJ, Iezzoni AF, Arús P (2003): Theor. Appl. Genet. 106: 819-825.

Bowers JE, Dangl GS, Meredith CP (1999): J. Enol. Vitic. 50: 243-246.

Bowers JE, Meredith CP (1997): Nat. Genet., 16: 84-87.

Carlier JD, Sousa NH, Santo TE, d'Eeckenbrugge GC, Leitao JM (2010): Mol. Breeding 29: 139-155.

Cipriani G, Spadotto A, Jurman I, Gaspero G, Crespan M, Meneghetti S, Frare E, Vignani R, Cresti M, Morgante M, Pezzotti M, Pe E, Policriti A, Testolin R (2010): Theor. Appl. Genet. 121: 1569-1585.

Doulati-Baneh H, Mohammadi SA, Mahmoudzadeh H, Mattia F, Labra M (2009): S. Afr. J. Enol. Vitic. 30 38-42.

Eujayl I, Sorrells ME, Baum M, Wolters P, Powell W (2002): Theor. Appl. Genet. 104: 399-407.

Fan-Juan M, Xiang-yang X, Feng-lan H, Jing-fu L (2010): Agric. Sci. China 9: 1430-1437.

Cheng Z, Huang H (2009): Sci. Hortic. 120: 188-193.

Ghețea LG, Moto RM, Popescu CF, Barbacar N, Iancu D, Constantinescu D, Barbarii LE (2010): Rom. Biotechnol. Lett. 15: 116-124.

Giannetto S, Velasco R, Troggio M, Malacarne G, Storchi P, Cancellier S, Nardi BD, Crespan M (2008): Plant Sci. 175: 402-409.
Gupta PK, Rustgi S, Sharma S, Singh R, Kumar N, Balyan HS (2003): Mol. Gen. Genomics 270: 315-323.

Huelsenbeck JP, Ronquist F (2001): Appl. notes 17: 754-755.

Jahnke G, Májer J, Varga P, Szöke B (2011): Sci. Hortic. 129: 32-37.

Jahnke G, Májer J, Lakatos A, Molnár JG, Deák E, Stefanovits-Bányai E, Varga P (2009): Sci. Hortic. 120: 213-221.

Jahnke G, Korbuly J, Májer J, Gyorffyné-Molnár J (2007): Sci. Hortic. 114: 71-73.

Jiang L, Ke-cheng Y, Guang-tang P, Ting-zhao R (2008): Agric. Sci. China 7: 1037-1045.

Jones CJ, Edwards KJ, Castaglione S, Winfield MO, Sala F, Wiel C, Bredemeijer G, Vosman B, Matthes M, Daly A, Brettschneider R, Bettini P, Buiatti M, Maestri E, Malcevschi A, Marmiroli N, Aert R, Volckaert G, Rueda J. Linacero R, Vazquez A, Karp A (1997): Mol. Breeding 3: 381-390.

Kozjak P, Koros Z, Koruza EC, Javornik B (2003): Vitis 42: 83-86.

Lamia K, Hedia B, Jean-Marc J, Neila TF (2010) Sci. Hortic. 127: 54-63.

Laucou V, Lacombe T, Dechesne F, Siret R, Bruno JP, Dessup M, Dessup T, Ortigosa P, Parra P, Roux C, Santoni S, Vare D, Péros JP, Boursiquot JP, This P (2011): Theor. Appl. Genet. 122: 1233-1245.

Lopes MS, Santos MR, Eiras-Dias JE, Mendonc D, Machado A (2006): J. Biotech. 127: 34-44.

Li-Xia W, Xu-Zhen C, Su-Hua W, Chang-You L, Hui L (2009): Acta Agron. Sin. 35: 816-820.

Ma QH, Wang GX, Liang LS (2011): Sci. Hortic. 129: 597-602.

Maghuly F, Borroto E, Ruthner F S, Pedryc A, Laimer M (2005): Tree Genet. Genom. 1: 151-165.

Martínez LE, Cavagnaro PF, Masuelli RW, Zúniga M (2006): Plant Sci. 170: 1036-1044.

McCouch SR, Teytelman L, Xu Y, Katarzyna B, Clare K, Walton M, Fu B, Maghirang R, Zhikang L, Xing Y, Zhang Q, Kono I, Yano M, Robert F, Genevieve D, Schneider D, Cartinhour S, Ware D, Stein L (2002): DNA Res. 9: 257-279.

Meng F, Xu X, Huang F, Li J (2010): Sci. Direct 9: (10) 1430-1437.

Moreno-Sanz P, Loureiro MD, Suárez B (2011): Sci. Hortic. 129: 433-440.

Nicerweb (2011) http://www.nicerweb.com/bio3400/ Locked/media/ch22/RFLP-pedigree.html 16.12.2011.

Oliveira AC, Garcia AN, Cristofani M, Machado MA (2002): Euphytica 128: 397-403.

Riaz S, Tenscher AC, Smith BP, Ng DA, Walker MA (2008): J. Amer. Soc. Horc. 133: 559-568.

Riaz S, Dangl GS, Edwards KJ, Meredith CP (2004): Theor. Appl. Genet. 108: 864-872.

Schneider A, Carra A, Akkak A, This P, Laucou V, Botta R (2011): Vitis 40: (4)197-203.

Sefc KM, Regner F, Turetschek E, Glossl J, Steinkellner H (1999): Genome 42: 367-373.

Sefc KM, Lopes MS, Lefort F, Botta R, Roubelakis-Angelakis KA, Ibanes J, Pejic I, Wagner HW, Glossl J, Steinkellner H (2000): Theor. Appl. Genet., 100: 498-505.

Sefc KM, Lefort F, Grando MS, Scott KD, Steinkellner H, Thomas MR (2001): Mol. Biol. Biotech. Grapevine 17: 434-460. 
Shimodaira, J (2002): Syst. Biol. 51: (3)492-508.

Song QJ, Shi J R, Singh S, Fickus EW, Costa JM, Lewis J, Gill BS, Ward R, Cregan PB (2005): Theor. Appl. Genet. 110: 550-560.

Thiel T, Michalek W, Varshney RK, Graner A (2003): Theor. Appl. Genet. 106: 411-422.

This P, Jung A, Boccacci P (2004): Theor. Appl. Genet. 109: 1448-1458.

Technologijahrane (2011) http://www.google.sk/imgr es?q=rapd \&um $=1 \&$ hl $=$ sk \& sa $=\mathrm{N} \& \mathrm{biw}=1920 \& \mathrm{bih}=971$ \&tbm=isch\&tbnid=2wwu28kFl0aqlM:\&imgrefurl=ht tp://www.tehnologijahrane.com/hemijahrane/pcrzasnovani-markeri\&docid=PDuiV_9LxuqmzM\&img url=http://www.tehnologijahrane.com/wp-content/ uploads/2009/06/umnozavanje-rapd-tehnikom.jpg\& $\mathrm{w}=858 \& \mathrm{~h}=668 \& \mathrm{ei}=\mathrm{UPHd}$ tyAPcbfsgasg $4 \mathrm{ySCQ \& zoo}$ $\mathrm{m}=1 \&$ iact $=\mathrm{rc} \& \mathrm{dur}=582 \& \mathrm{sig}=113483999905443614957$ \&page $=1 \&$ tbnh $=127 \&$ tbnw $=167 \&$ start $=0 \&$ ndsp $=67 \&$ ve $\mathrm{d}=1 \mathrm{t}: 429, \mathrm{r}: 9, \mathrm{~s}: 0 \& \mathrm{tx}=90 \& \mathrm{ty}=39 \mathrm{n}$ 16.12.2011.

Tessier C, David J, This P, Boursiquot JM, Charrier A (1999): Theor. Appl. Genet. 98: 171-177.

Thomas MR, Scott NS, Botta R, Kijas MH (1998): J. Japan. Soc. Hortic. Sci. 67: 1189-1192.

Troggio M, Malacarne G, Coppola G, Segala C, Cartwright DA, Pindo M, Stefanini M, Mank R, Moroldo M,
Morgante M, Grando MS, Velasco R (2007): Genetics 176: 2637-2650.

Ulanovsky S, Gogorcen Y, Martiney De Toda, F., Ortiz, JM (2002): Sci. Hortic. 92: 241-254.

Upadhyay A, Saboji MD, Reddy S, Deokar K, Karibasappa GS (2007): Sci. Hortic. 112: 176-183.

Varshney R K, Sigmunda R, Borner A, Korzunb V, Steina N, Sorrells ME, Langridged P, Graner A (2005): Plant Sci. 168: 195-202.

Vezzulli S, Troggio M, Coppola G, Jermakow A, Cartwright D, Zharkikh A, Stefanini M, Grando MS, Viola R, Adam-Blondo AF (2008): Theor. Appl. Genet. (doi:10.1007/s00122-008-0794-3).

Vignani R, Bowers JE, Meredith CP (1996): Sci. Hortic. 65: 163-169.

Wunsch A: (2009): Sci. Hortic. 120: 348-352.

Xie R, Li X, Chai M, Songa L, Jiaa H, Wub D, Chenb M, Chen K, Aranzanac MJ, Gaoa Z (2010): Sci. Hortic. 125: 622-629.

Ya-Ming G, Sheng-chun X, Wei-hua M, Ze-yun L, Qi-zan H, Gu-wen Z, Ju D (2011): Agric. Sci. 10: 838-844.

Zhang L, Li Z, Wang Y, Jiang Z, Wang S, Huang H (2010): Euphytica 175: 133-143. 